\title{
Coding and traceability for cells, tissues and organs for transplantation
}

\author{
D. Michael Strong $\cdot$ Naoshi Shinozaki
}

Received: 27 April 2010/Accepted: 28 April 2010/Published online: 13 May 2010

(C) Springer Science+Business Media B.V. 2010

\begin{abstract}
Modern transplantation of cells, tissues and organs has been practiced within the last century achieving both life saving and enhancing results. Associated risks have been recognized including infectious disease transmission, malignancy, immune mediated disease and graft failure. This has resulted in establishment of government regulation, professional standard setting and establishment of vigilance and surveillance systems for early detection and prevention and to improve patient safety. The increased transportation of grafts across national boundaries has made traceability difficult and sometimes impossible. Experience during the first Gulf War with miss-identification of blood units coming
\end{abstract}

\section{M. Strong}

Department of Orthopaedics and Sports Medicine, University of Washington School of Medicine,

Seattle, WA, USA

D. M. Strong $(\square)$

18624, 94th Ave West, Edmonds, WA 98020, USA

e-mail: dmichaelstrong@mac.com

N. Shinozaki

Department of Ophthalmology, Ichikawa General

Hospital, Tokyo Dental College, Ichikawa City, Japan from multiple countries without standardized coding and labeling has led international organizations to develop standardized nomenclature and coding for blood. Following this example, cell therapy and tissue transplant practitioners have also moved to standardization of coding systems. Establishment of an international coding system has progressed rapidly and implementation for blood has demonstrated multiple advantages. WHO has held two global consultations on human cells and tissues for transplantation, which recognized the global circulation of cells and tissues and growing commercialization and the need for means of coding to identify tissues and cells used in transplantation, are essential for full traceability. There is currently a wide diversity in the identification and coding of tissue and cell products. For tissues, with a few exceptions, product terminology has not been standardized even at the national level. Progress has been made in blood and cell therapies with a slow and steady trend towards implementation of the international code ISBT 128. Across all fields, there are now 3,700 licensed facilities in 66 countries. Efforts are necessary to encourage the introduction of a standardized international coding system for donation identification numbers, such as ISBT 128, for all donated biologic products.

Keywords Coding - Traceability . Tissues · Organs · Cells · Transplantation · ISBT 128 


\section{Background}

Development of cell, tissue and organ transplantation

The history of skin grafts has its beginnings in ancient India, where Sanskrit texts document skin transplants performed by Hindus in 3000-2500 BC (Herman 2002). The concept of transplantation of body parts from one individual to another can be found in paintings from the Middle Ages depicting the transplanting of a leg from an African donor to an Italian noble. Even grafting of animal bone to a human was described as early as 1668. The first clinical autograft was performed in Germany in 1820 and the first human bone allograft in 1880 in Scotland (DeBoer 1986). Eduard Zirm performed the first corneal transplant in Vienna, Austria in 1905, initiating this practice in ophthalmology (Moffat et al. 2005). Alexis Carrel is credited with the earliest studies on the storage of tissues and was prophetic in his predictions of the use of cadavers for organ and tissue donation. He was the first to transplant vascular tissues (Carel 1912) and was the recipient of a Nobel Prize.

The use of banked tissues in surgical procedures is credited to Albee who used both autologous and allogeneic-banked bone as early as 1910 (Albee 1912). The first eye bank opened in New York in 1944, marking the first organized attempt at banking donor tissue, facilitating the transfer of eye tissue from donor to recipient. It wasn't until the 1940s that bone banking became common practice, primarily with autologous grafts (Wilson 1947; Bush and Garber 1948). Established in 1961 by the American Academy of Ophthalmology's Committee on Eye Banks, the Eye Bank Association of America is the oldest national transplantation association, leading the transplant field with the establishment of medical standards for the procurement and distribution of eyes, comprehensive education programs for technicians, and accreditation of eye banks. Modern day tissue banking was initiated in the US Navy in 1949 and many of today's standards are due to their experience over several decades along with the establishment of the American Association of Tissue Banks (AATB) in 1976 (Strong 2000). By the early 1950s, tissue banks were also established in Europe.
By 1971, the recognition that ionizing radiation was being used to sterilize tissue (non-ocular) engaged the International Atomic Energy Agency (IAEA), which sponsored an expert meeting in Hungary (Phillips and Strong 1997). Over the ensuing years, assistance was provided to developing countries in both Asia and South America and workshops, training programmes and educational materials were provided. Support for Tissue Banks was provided for: Argentina, Bangladesh, Brazil, Chile, China, Cuba, India, Indonesia, Republic of Korea, Malaysia, Pakistan, Philippines, Singapore, Sri Lanka, Thailand and Vietnam. In addition training scholarships were provided for individuals from these countries as well as participants from countries such as Algeria, Turkey, Hungary, Costa Rica, Peru, Mexico and Zambia to train in established tissue banks in Europe and the United States. As an example of the success of these programmes, the Sri Lanka Eye Donation Society had distributed over 33,000 corneas by the mid 1980s.

The early clinical success with bone and corneal transplants was due to the non-vascularized nature of such grafts. The use of organs was impeded until the recognition of the histocompatibility system, first described in 1951 (Billingham and Medawar 1951), which led to a Nobel Prize. Their work also led to the discovery of glycerol as a cryopreservative for skin thus opening the possibilities for skin banking for the treatment of burns. Dr Joseph Murray performed the first successful kidney transplant, between identical twins, in 1954, which also led to a Nobel Prize and the advent of solid organ transplantation (Guild et al. 1955). Dr Murray shared the Prize with Dr E. Donnell Thomas who was instrumental in advancing the field of bone marrow transplantation (Thomas et al. 1957). Both the solid organ and stem cell transplantation fields have been able to progress due to advances in immunosuppressive drugs and histocompatibilty matching. Establishment of organ sharing networks in developed countries such as the United Network for Organ Sharing in the U.S. and Eurotransplant for some countries in Europe, along with registries for unrelated stem cell transplants such as the Anthony Nolan Trust in the United Kingdom, OneMatch in Canada and the National Marrow Donor Program in the U.S. have expanded the scope and ability to share these valuable resources worldwide. 
Advances in healthcare technologies have led to an increasing number and wider array of tissues of human origin being collected to sustain and improve the quality of life. Solid organs, corneas and eye tissues, including sclera, bone, skin, and stem cells, are all examples of human tissues derived from living or deceased donors, otherwise known as allografts. In the United States in 2007, 28,000 organs, 50,000 corneas, 18,000 stem cell grafts and over two million tissue allografts were distributed. Despite the increase in numbers over time, demand often exceeds supply, particularly for solid organs. In the U.S., over 100,000 patients are on waiting lists for organ transplants. Efforts to increase the availability of these vital products generate challenges to monitor and ensure appropriate access and safety both in the domestic and global arenas since these products often cross national boundaries. Moreover, the lucrative nature of the selling of socalled "body parts" has generated unethical behavior. Recent scandals such as the trafficking of solid organs sold from Israel to New York (Feyerick 2009) and the alleged theft of tissues from Ukraine (Keller and Grill 2009) have generated much interest in the press and exemplify the global nature of the problem (Chaney 2006). In addition to importation of organs and tissues, patients are traveling abroad to receive organ transplants and thus the risk of importing new diseases in immunosuppressed recipients is amplified.

Noting the global increase in allogeneic transplantation of cells, tissues and organs, the World Health Organization (WHO) urged member states:

To implement effective national oversight of procurement, processing and transplantation of human cells, tissues and organs, including ensuring accountability for human material for transplantation and traceability.

To cooperate in the formulation of recommendations and guidelines to harmonize global practices in the procurement, processing and transplantation of human cells, tissues and organs, including development of minimum criteria for suitability of donors of tissues and cells.

To consider setting up ethics commissions to ensure the ethics of cell, tissue and organ transplantation.

To extend the use of living kidney donations when possible, in addition to donations from deceased donors.
To take measures to protect the poorest and vulnerable groups from "transplant tourism" and the sale of tissues and organs, including attention to the wider problem of international trafficking in human tissues and organs (WHO 2006).

Risks associated with cells, tissues and organs

The transmission of infections or malignancies to recipients of solid organs, tissues, and eye grafts is well documented (Fishman 2007; Eastlund and Strong 2004; Trotter 2008; Tugwell et al. 2005; Gandhi and Strong 2007). Infectious pathogens can include viruses, bacteria, parasites and prions. The risks of amplification of transmission increase when there are multiple recipients from a common donor since as many as 100 tissues and organs can be recovered from a single donor. Due to the organ shortage in particular, donors with known high-risk behavior are sometimes accepted for organ transplantation which can result in multiple infectious risks (Ahn and Cohen 2008). Other adverse events can occur including malignancies, reactions to toxins, unexpected malfunction, adverse immunological responses and immune mediated disease transmissions and administrative errors.

In addition, the organ, tissue and eye banking communities function independently and communication between them is inconsistent and often lacking. This lack of a formal communication can result in an inability to track organs and tissues from a common donor. For example, a report in 2005 described a number of hepatitis $\mathrm{C}$ virus (HCV) transmissions to several organ and tissue recipients from a single donor. This case generated much publicity because there were 91 grafts produced from the donor (7 organs, 2 corneas and 82 other tissues), 44 transplants and 40 recipients in 16 states and 2 other countries over a period of 22 months. Three organ recipients were infected and 32 of the tissue recipients could be identified and tested of which 5 were HCV positive and infected. To date, no recipient of the transplanted eye tissue has seroconverted (thus, the recipients remain $\mathrm{HCV}$ negative). One tissue recipient could not be identified. All of the tissue recipient infections would have been prevented if recognition of infection in the organ recipients had resulted in notification of the tissue bank before tissue was processed or released. More than 6 months elapsed between recognition of the organ recipient 
infections, donor linkage, and the time that tissue was processed (Tugwell et al. 2005). Events of this nature can only be avoided by the introduction of a comprehensive and unified traceability system covering all biologics derived from a single donor.

The recall of allograft tissues in the U.S. underscores the problem related to allograft safety. The FDA, between 1994 and June 2007, recalled 61,607 tissue allografts. The vast majority of these $(59,476$ or 96.5\%) were musculoskeletal allografts (Mroz et al. 2008).

Biologic-based products or technologies are always likely to carry an inherent risk. While solid organs and some tissues such as the cornea cannot be altered to reduce infectivity, some tissue types can be processed with chemicals or radiation For instance, blood can be modified through leukocyte filtration or irradiation. However, no process can eliminate the risk of transmission. The role of patient safety efforts is to drive that risk to the lowest level reasonably achievable without unduly decreasing the availability of these life saving resources, so that the overall benefit outweighs risk. Risk must also be assessed using vigilance and surveillance programmes which to date have not been universally developed for tissues and cells and are insufficiently developed for organs through regional organ sharing programmes such as UNOS in the U.S. The U.S. does require mandatory reporting of infectious adverse reactions to the FDA by regulated establishments, and eye banks accredited by the EBAA comply with requirements to electronically report adverse reaction, including those due to biologic dysfunction. The successes of this reporting is made possible since eye banks typically distribute ocular tissue directly to the surgeon and identify the recipient prior to transplantation. A critical component of a biovigilance system is constructive feedback to ongoing analysis efforts. The World Health Organization (WHO) guideline on adverse event reporting emphasizes that the effectiveness of surveillance systems should be measured not only by transplant outcome data reporting and analysis but also by the use of such systems to improve patient safety through active response to data that are generated (WHO 2005).

Vigilance and surveillance of tissues and cells used in transplantation is a recent development all over the world. Biovigilance was established in France by a decree in 2003. The European Union
Standards and Training for the Inspection of Tissue Establishments (EUSTITE) co-funded by the European Commission, is assisting member states by providing guidance documents and training in the areas of inspection and adverse event and reaction reporting. The project has developed vigilance and surveillance tools consistent with and complementary to those existing, such as hemovigilance systems, and under development globally. The Department of Essential Health Technologies at the WHO has led these efforts. A survey of member states conducted early in the project indicated that most countries did not have a system of vigilance in place for tissues and cells. In line with the requirements of the European Tissue and Cell Directives, almost all member states have now set up such systems. The EUSTITE vigilance tools have been piloted in 20 Member States during 2008/2009 and over 300 adverse events and reactions have been reported and assessed using the tools. These tools are able to objectively evaluate severity and imputability as well as impact assessment of adverse reactions and events. The key elements of the tools have been incorporated into guidance produced by the European Commission to member states for the compilation of their annual vigilance reports.

Challenges for traceability of cells, tissues and organs

During 2005, a report from the state of New York in the U.S. identified a serious problem with tissue recovery being done outside of all standards and regulations. It was discovered that a non-AATB accredited organization was recovering donors from funeral homes without the permission of families, without adequate medical screening, and were, in many cases, falsifying records. Tissue was sold to a number of tissue processing centres and distributed. Over 1,000 donors were recovered during a threeyear period of time. Nearly 50,000 tissues were produced of which 15,000 could be recalled prior to transplantation. Over 25,000 tissues were distributed to unsuspecting patients without appropriate testing or medical review (Warren 2006). Because records from these donors had been forged, over 2,000 of these tissues were untraceable including 800 that had been distributed outside of the United States. The real concern however, is that even apart from these 
unusual scandals, there is not a uniform system for tracking many tissues, with the exception of corneal tissue, or to detect adverse events from their use. In fact, most of the reported infectious transmissions from tissue transplants have included the inability to identify common recipients of tissues from the same donor (applicable to tissues, not eyes).

Voluntary standard setting organizations, such as the AATB and the European Association of Tissue Banks (EATB) in Europe, have published standards which require facilities that store and issue tissue, including tissue distribution intermediaries, to maintain an adverse reaction file, develop recall procedures and report adverse events and reactions to Tissue Banks. Tissue Banks are required to maintain adverse event policies and procedures including reports that must be reviewed by the Medical Director. Tissue Banks also include transplant records/implant cards with each allograft that is distributed. These records contain graft information. Hospitals are requested to return these records following transplants, although this is not required of healthcare facilities, unless accredited by the Joint Commission (TJC). Unfortunately, unless accredited by the TJC, compliance with returns cannot be enforced, which can hinder investigations and traceability. AATB also perform periodic surveys of its members to determine statistics concerning donation and distribution. These surveys have demonstrated that compliance with the return of transplant records ranges from 10 to $95 \%$ thus further emphasizing the difficulties with traceability.

In 1991, the Medical Advisory Board of the The Eye Bank Association of America (EBAA) instituted a requirement for its member eye banks to seek three to twelve month follow-up reporting of all cornea recipient outcomes. Their Adverse Reaction Registry System (OARRS) was redesigned in 2005 for online submissions of adverse reactions deemed "reasonably likely due to donor tissue." Through its Medical Advisory Board, OARRS submissions are reviewed and reported to EBAA members on a biannual basis. Eye banks employ a number of methods to seek the follow-up outcomes, including regular mailings to transplant surgeons, as well as providing institutions with adverse reaction reporting forms. Information submitted through OARRS includes a description of the adverse reaction, date of surgery, microbiology results, tissue mate status, data about the donor.
EBAA requires its members to seek recipient information and outcomes as part of its accreditation process. With a limited number of non-stocked ocular tissues being distributed per donor, compliance is easier to attain for eye banks.

In response to increased recognition of fatal events due to diseases transmitted through organ transplantation, there are relatively new policies in place to require reporting of suspected disease transmission, that are in the process of implementation. In the US these efforts include the creation of a UNOS Disease Transmission Advisory Committee (DTAC) to facilitate and monitor reports of organ donor-derived practices for organ donors. These reports are required under new UNOS policy. A total of 97 reports of possible solid organ transplantation transmission were reported to federal authorities in 2007 alone, affecting a significant percentage of the recipients of over 28,000 organ transplantations annually. Recently an estimate of the scope of disease transmission has been roughly placed as involving approximately $1 \%$ of recipients (Ison et al. 2009).

The Center for International Blood and Marrow Transplant Research (CIBMTR) manages data on hematopoietic cellular therapies (HCT) through an affiliation with the International Bone Marrow Transplant Registry (IBMTR) of the Medical College of Wisconsin and the research arm of the National Marrow Donor Program (NMDP). IBMTR is a voluntary organization involving more than 400 transplant centers in 50 countries that have collaborated to share patient data and conduct scientific studies since 1972. They collect data from all U.S. stem cell transplants and from about $25 \%$ of the rest of the world. The NMDP was formally established in 1987 to provide unrelated donors for patients in need of HCT. Their network includes 164 transplant centers, 80 donor centers, 101 collection centers, 89 apheresis centers and 17 cord blood banks (CIBMTR Progress Report 2008). Data are collected annually on transplant recipients including follow-up information on previously reported patients and adverse reactions. Adverse events and reactions are also monitored at the local center level using a variety of center/hospital specific definitions.

In 2005 the Joint Commission (TJC) in the U.S. published standards relating to tissue storage and issuance. TJC accredits and certifies more than 15,000 health care organizations and programs in 
the United States. One of the problems associated with the lack of traceability was the recognition that tissue is often dispersed among a variety of surgical services with no central management, unlike traceable blood and pharmaceuticals which are distributed within the hospital via licensed/accredited laboratories and pharmacies, and organs where the recipient is identified and recorded prior to the donation event, tissue are distributed and stored within surgical environments and can be mistaken and utilized as mere 'consumables'. Therefore the new standards require the assignment of responsibility for handling tissue within a hospital to a single coordinating entity. The oversight responsibility includes: supplier certification, incoming inspection and logging in of tissue, traceability and record keeping, storage temperature monitoring, investigation of adverse outcomes, reporting tissue-related infections to the tissue supplier, sequestering tissue reported by the supplier as contaminated, the notification of surgeons and recipients if tissue donors are subsequently found to harbor infection, and compliance with federal and state regulations if supplying tissues to any other facility. Although compliance with TJC standards is voluntary, most hospitals in the U.S. comply with TJC requirements in order to qualify for Medicare reimbursement, and the College of American Pathologists (CAP), the accrediting body of most hospital laboratories, has adopted similar requirements. In many cases, hospitals have turned to their blood bank where many of these capabilities are already in existence.

Professional Associations also responded to the problems of traceability by strengthening their standards and working to harmonize their standards with that of the TJC. The AABB (formerly the American Association of Blood Banks, both modified their standards as well as published a series of handbooks to assist hospital transfusion services to manage tissue (Eisenbrey and Eastlund 2008).

The increased recognition of issues related to traceability has also resulted in various governmental actions in addition to existing regulations. In June 2005, the U. S. Centers for Disease Control and Prevention (CDC), Food and Drug Administration (FDA), and Health Resources and Services Administration (HRSA) convened a workshop entitled "Preventing Organ and Tissue Allograft-Transmitted Infection: Priorities for Public Health Intervention."
Attendees included members from blood, organ and tissue communities along with government representatives. This workshop identified gaps in organ and tissue safety in the United States (Fishman et al. 2009). Four areas for possible intervention were identified:

1. Communication among organ procurement organizations (OPOs), tissue banks, clinicians and public health agencies related to donors, samples and test results;

2. Tissue bank systems for tracking and notification of testing;

3. Hospital systems for tracking organs and tissues;

4. Recipient adverse event recognition. The workshop concluded that the most critical need was for development of a communication network for the tracking and reporting of disease transmissions for tissues and organs. Such a network would require a unique donor identifier linking organs and tissues, a tracking mechanism for all allografts, and processes for reporting of adverse events for the notification of clinicians, patients, and public health authorities.

As a result of the 2005 workshop, CDC published a Request for Proposal for the development of a "Sentinel Network for Detecting Emerging Infections Among Allograft Recipients" (Federal Register 2005). The United Network for Organ Sharing (UNOS) on behalf of an alliance including: The Association of Organ Procurement Organizations (AOPO); the AATB; the Eye Bank Association of America (EBAA); the American Society of Transplantation (AST); and the American Society of Transplant Surgeons (ASTS) submitted a proposal and entered into a cooperative agreement with CDC in 2006 to develop what was called the Transplantation Transmission Sentinel Network (TTSN). The purpose of the network was to provide a system for detecting emerging infections among allograft donors and recipients and aid healthcare personnel in detecting, communicating, tracking and preventing the transmission of infections.

A Transplantation Transmission Sentinel Network (TTSN) data base prototype was created by UNOS over a three-year cooperative agreement (and oneyear extension) with CDC. A pilot study was carried out after development of a prototype, which led to a number of conclusions. Unfortunately, no additional 
funding was available to take the system to production. TTSN was an important step forward in determining the needs for a national system integrating organ and tissue safety. Lessons learned included the need to create a partnership with two separate industry groups, the solid organ transplant community and tissue banking and user community. Building an adverse event system without a foundation of existing nomenclature or tracking for tissue allografts resulted in a daunting task to organize what is essentially a chaotic environment. The prototype proved that a system can be built, however, only with an impetus from legislation or regulation to track allograft use nationally and internationally. The lack of a uniform labeling standard in the U.S. and other countries, as exists for blood and blood products, may also contribute to the problems of tracking and traceability. The key to satisfying these requirements lies in standardization: globally unique identifiers for products, standardized terminology and a means to convey information electronically that is recognized by computer systems throughout the world.

Importation and exportation of cells, tissues and organs across national boundaries

In the previously reported Biomedical Tissue Services (BTS) scandal, there were more than 800 tissues that couldn't be traced outside the U.S. More than 25 hospitals in the United Kingdom alone reported receiving tissues from this case. The AATB reports that US tissue banks export tissue to more than 30 countries. A survey of the 5 largest US tissue banks demonstrated that from 2 to $8 \%$ of their distributions are international with major markets in: Korea, Turkey, Greece, Canada, the Middle East, Central American, South America, Australia and the EU. In Canada, over $90 \%$ of tissue transplanted is imported from the U.S. In the BTS recall, Health Canada was only able to provide approximate estimates of the number of recalled tissue products imported into Canada and was dependent on multiple tissue banks and tissue importers for tracing allografts to end users and notifying patients (Health Canada News Release 2005). The US FDA investigations in 1993 documented the legitimate importation of tissue by some US banks from Eastern Europe (Henkel 1994). The trafficking of solid organs sold from Israel to New York (Feyerick 2009) and the alleged theft of tissues from Ukraine (Keller and Grill 2009) are other examples of international trade. It is also worth noting that donated tissue may be from a non US source, processed in the US and issued in and out of the US, making traceability even more complex.

For cellular therapies, the Cellular Therapy Coding and Labeling Advisory Group began its work in 2004. Over $40 \%$ of unrelated bone marrow donations are transplanted in a country other than the one where they were donated. Unrelated cord blood donations are increasingly being exported around the world for stem cell replacement. This is a steady upward trend from just 30\% in 1997. Recognizing the high proportion of grafts crossing national borders, the US FDA published in the Code of Federal Regulations (21CFR 1271.55), rules governing imports. These included that cells and tissues must have distinct identification codes that relate to the donor and to all records pertaining to the graft. Import and export regulations of cell therapy products are based on the FDA's risk based approach, recognizing the need for traceability.

Corneas are also exported on a large scale. The Eye Bank in Sri Lanka exports corneas to 65 countries and claims to have exported over 40,000 corneas since it's founding in 1964. It is common practice in the US to export corneas to Africa and South America where the need is great and the supply scarce. Over 10,000 corneas are exported from the US each year. The total numbers of cell, tissue and organ exports is not known since there is no central control or agency that captures this data.

\section{Recognition of the need for global standardization}

The need for globally unique identification

Blood Services have long recognized the need to ensure that each unit of blood can be individually identified in order to relate sample test results and cross matching outcomes to the correct unit, and to allow tracking from donor to recipient. Initially each blood center assigned its own numbers to the units it collected, and ensured uniqueness of identification within its organization and the transfusion services it served.

With the introduction of policies in some countries to share blood resources between blood centers in order to more effectively satisfy supply and demand, 
a need was recognized for blood unit identification to be unique at a national level to prevent duplication of numbers in hospital transfusion laboratories. Without this capability, patient safety is at risk as exemplified by the common problem of misidentification of patients and wrong blood units being transfused, sometimes resulting in death.

The experience during the Persian Gulf War in 1990 and 1991 was the primary stimulus to solve the labeling and coding issues. Because the military contracted with many agencies to provide blood, the military experienced thousands of labeling mistakes resulting in misidentification of units (Blood Products Advisory Committee 1997). Additionally, during the 1990s it became increasingly common to establish centralized testing laboratories. When multiple blood centers submitted their samples to a single laboratory for testing, identifiers were often unique only within the context of the facility in which products were drawn. The International Society of Blood Transfusion (ISBT) established a Working Party, with international membership from multiple countries, which created a standardized means of labeling blood products so that identifiers were globally unique and bar codes (as well as other means of electronic information transfer) would have the same meaning internationally. The new coding system was named ISBT 128, the ' 128 ' in ISBT 128 comes from the barcode symbology which was selected at the time the standard was developed-this symbology is called Code 128, so the ISBT coding system using Code 128 bar codes became known as ISBT 128. This standard was formally approved in 1994.

Although the transfer of blood across national boundaries is not a common occurrence, the situation for cells and tissues is very different as has been indicated above. For this reason the case for globally unique identification is at least as strong as that for blood transfusion. A globally unique identification system is required, and this should extend across all biologic materials-blood, cells, tissues and organs.

Previous experience gained from managing adverse events and reactions has led to a widespread understanding of the need for traceability - the ability to track from donor to recipient and vice versa in order to ensure that all individuals associated with an event or reaction can be identified. Full traceability goes well beyond the single strand of information following the path of one product from donor to recipient, and becomes a complex web where multiple products are produced, pooled products are prepared, donors can make multiple donations of different biologic materials and multiple agencies can be involved in the procurement of organs and tissues. This web of information has multiple data owners, frequently extends across continents, and has to be retained for long periods of time (European Tissues and Cells Directive requires information to be stored for 30 years from the time of clinical use).

Retaining such large amounts of information for long periods in a format that allows rapid retrieval demands the use of computer data storage. In order to ensure a complete and secure information trail across the multiple computerized systems that may be involved, a means of uniquely identifying each donation, and each product prepared from that donation, is essential. It is clear that uniqueness of identification at national or regional level is not sufficient when cells, tissues and organs can and do travel worldwide.

WHO guiding principles

WHO has held 2 global consultations on human cells and tissues for transplantation, the first in Ottawa in December 2004 and the second in Geneva in June 2006, both of which resulted in reports. Participants recognized the significant global circulation of certain human tissues and cells and the substantial roleplayed by a commercial market in many of these tissue and cell products. Transparency in these activities is essential to ensure public support and understanding. A key element of oversight includes effective systems of vigilance and surveillance worldwide, which requires, as an essential prerequisite, a robust system for traceability of donated material from donor to recipient. WHO is participating in a EU funded project that is working to develop common systems for the reporting and management of adverse events and reactions (EUSTITE). The WHO has clearly stated its position concerning coding and traceability of cells, tissues and organs. At the Second Global Consultation on Regulatory Requirements for Human Cells and Tissues for Transplantation in 2006, the WHO published a statement that "As this globalization of cells and tissue transplantation develops, the need for common product names and definitions for unique product identification becomes essential”. 
The updated WHO Guiding Principles on Human Cell Tissue and Organ Transplantation as approved by the 124th Executive Board in resolution 124.R13 includes Guiding Principle 10 dedicated to the necessity of detailed assessment of transplantation procedures as well as of the outcome of transplanted human cells, tissues and organs. In the commentary of Guiding Principle 10 is the following sentence: "Internationally agreed means of coding to identify tissues and cells used in transplantation are essential for full traceability".

Work carried out during and after the two Global consultations has resulted in the development of two WHO Aide-Memoires specifying basic requirements in this field. The Aide-Mémoire on "Access to Safe and Effective Cells and Tissues for Transplantation" provides an overview for National Health Authorities, but also for all stakeholders, of all key aspects to be considered and requirements to be met for the setting up and/or the oversight of human cell and tissue transplantation services (WHO 2009).

\section{European directive and CEN workshop}

In 2004, a European Union Directive mandated a single coding system for cells and tissues [European Tissues and Cells DIRECTIVE 2004/23/EC (ECD)]. To this end, the European Committee for Standardization (or Comité Européen de Normalisation or CEN) evaluated various standardized coding systems for use within the European Union (CEN Workshop Agreement 2008). It was recognized that “...there are real problems with meaning-shift when using common terms between languages. For that reason many nomenclature schemes use a very rigid set of syntactical rules to ensure that the term being coded is capable of being interpreted faithfully in any language, whatever its real-world syntax and grammar". The report promoted ISBT 128 as the preferred option but they also proposed allowing member states to use two other variations (one with national ID numbers but ISBT 128 product descriptions and one without any internationally agreed component). They determined that one of the major benefits of ISBT 128 was that it could be used for four groups of biologics: blood, cells, tissues and organs. The CWA work analyzed existing relevant public activities at European, national, regional and international levels, and also considered relevant international activities. There were 3 candidates proposed by Member State (MS) and a panel recommended use of ISBT 128 as the basis for the EU coding scheme. Although it was considered a good match to requirements, it was not perfect in its current design. Further work was identified to meet the need for an additional component to be created to support both use of ISBT 128 and those organizations electing to retain existing coding schemes. This new component was temporarily named in the CEN report as the "key code". Because a donation event may result in tissues sent to different Tissue Establishments ICCBBA offered a new component, incorporating Country code, Responsible organization (e.g. Competent Authority) and Tissue Establishment, to be developed with the EU to meet international requirements. The Key Code would not invalidate existing ISBT 128 code structures but augment them. The "key code" could also be used with existing coding systems to provide unique identification and allow EU (potentially global) traceability of all materials from one donation event. Among the other CEN CWA conclusions were:

1. The ability to share coded data between different donor sectors in the future may help with risk prevention measures and provide clearer indications of donor suitability.

2. It may also reduce duplication and ensure better recall management.

3. It is feasible that with technological advances in regenerative medicine that the interfaces between blood, tissues, cells, and organs may become less defined.

The CEN solution supports the long-term migration to ISBT 128 whilst providing a short-term solution to unique identification through the use of the key code.

In transposing the EC Directive into national legislation, some countries (notably Poland and Austria) made the use of ISBT 128 for coding and labeling cells and tissues a legal obligation.

Mechanisms for providing globally unique identification

A number of mechanisms exist for providing globally unique identifiers, and in general when a large number of items have to be identified, they work on a layered principle. An overarching international 
body assigns a portion of the identifier to reference an organization responsible for lower level assignment, and the sub-body assigns unique identifiers within its jurisdiction. Together the two parts provide a unique identification. An example is the telephone numbering system where a United Nations Agency, the International Telecommunications Union, assigns the 'country code' and the actual number of each telephone in the country is assigned by a 'national' body. (Although 'country code' is used in this context, it is not an exact match to country identification-for example the country code ' 1 ' covers both the USA and Canada.)

A similar mechanism is used by GS1, the supply chain standards body that maintains the GS1 standard used by many commercial organizations for bar coding their products. Using GS1, each type of product from a manufacturer can be uniquely identified using a Global Trade Item Number (GTIN). GS1 assigns one portion of the GTIN identifier to uniquely identify each manufacturer, and the manufacturer assigns the second portion to uniquely identify the type of product within their organization.

In the transfusion and transplantation field, ICCBBA uses a similar model by assigning a facility code to each organization that will assign ISBT 128 donation identification numbers (e.g. blood center, tissue establishment, competent authority) and the relevant organization assigning a sequence number.

In all the above cases the combination of the two elements provides a globally unique identification for the item or, in the case of tissues, the donation event.

The case for bar coding and electronic data transfer

Traceability depends not only on the use of unique identifiers, but also on the accurate transcription of those identifiers at all parts of the traceability chain. The risks of error during manual transcription of information are well documented, and in the blood transfusion field, which has some well-developed hemovigilance systems, cases of incorrect blood component transfused are a major source of adverse events, with administrative errors in identification forming a major cause of these. Use of electronic information capture provides a means of improving safety by eliminating the risk of manual transcription error, and speeding up the information transfer process.
Clearly not all countries have the necessary infrastructure to support the use of computerized systems throughout the transplant process, however where systems are available they should be used, and the ability to introduce such safety measures should not be impeded by the lack of bar coded information on the tissue product label. For this reason, any move towards adopting globally unique identification should be compatible with a well established standard coding system so that the progression towards automated data capture and computerized records can be achieved.

\section{Coding systems}

What is a coding system?

A coding system is a means by which distinct items within a system can be uniquely identified and consistently characterized to all participants within that system. It requires as a minimum a means to allocate identifiers in a manner that avoids duplication, and a standard reference for describing items.

The degree to which unique identification is required depends upon a number of factors. For a manufactured drug identification of the manufacturer and the unique lot number assigned by that manufacturer is sufficient to trace back to the manufacturing records for the batch. In this situation it is common to use a single identifier for all items in the batch. For donated biologics such as blood or tissue each donation has unique characteristics and is thus a 'batch' in its own right. In such cases there is a need for unique identification to be at the individual donation level, and for each product prepared from the donation to also be individually identified.

Uniqueness within a system requires that a boundary be defined to the system and controls need to be in place to ensure that the item does not travel outside the boundary. If, for example, the system is contained within a national boundary, then uniqueness at the national level is adequate, but as soon as an item travels beyond the boundary, the risk of duplication exists. For biologic products, which increasingly travel worldwide, global uniqueness is essential.

With the increasing use of computers, coding systems are commonly associated with information standards to allow the coding information to be electronically transmitted between computer systems. 
Typically the coded information is presented in an electronically readable format such as a bar code. The information standard defines the technical specification for this electronic format thus ensuring that all computer systems can read and write the electronic information.

It is important to recognize that a coding system does not itself provide traceability, but provides the information infrastructure on which effective traceability can be built. Coding and traceability are not the same but one supports the other.

\section{Coding systems and traceability}

Previous experience gained from Blood in managing adverse events and reactions has led to a widespread understanding of the need for traceability - the ability to track from donor to recipient and vice versa in order to ensure that all individuals associated with an event or reaction can be identified.

There is frequently confusion regarding the terms 'coding system' and 'traceability system'. These are perceived to be the same, but in fact they are quite distinct. A coding system provides the necessary standards and control in order to ensure that each donation, and each product prepared from that donation, is uniquely identified, and that a common terminology is used. A traceability system maintains records on the activities associated with donated material from the time of procurement to the point of implantation.

Where the full lifecycle of donated material occurs within the boundary of a single traceability system, the identifiers and terminology used can be specific to that traceability system. However, as soon as traceability responsibility is distributed across several traceability systems there is need for an underlying coding system that provides global uniqueness of identification and internationally agreed terminology.

The EU Commission Directive 2006/17/EC defines traceability as follows:

'Traceability' means the ability to locate and identify the tissue/cell during any step from procurement, through processing, testing and storage, to distribution to the recipient or disposal, which also implies the ability to identify the donor and the tissue establishment or the manufacturing facility receiving, processing or storing the tissue/cells, and the ability to identify the recipient(s) at the medical facility/facilities applying the tissue/cells to the recipient(s); traceability also covers the ability to locate and identify all relevant data relating to products and materials coming into contact with those tissues/cells.

This definition focuses on the single path from donor to recipient; however, full traceability requires all tissue, and arguably all biologics (blood, cells, tissues and organs) from the same donor to be traced. Full traceability goes well beyond the single strand of information following the path of one product from donor to recipient, and becomes a complex web where multiple products are produced, pooled products are prepared, donors can make multiple donations of different biologic materials and multiple agencies can be involved in the procurement of tissues. Almost inevitably this means that the traceability path will travel through multiple traceability systems. There may be situations where traceability is required beyond a single donation where a donor may donate multiple components via multiple establishments throughout their life e.g. Cord blood, blood, sperm, hip bone, and on death, organs, corneas and multi-tissues. Should a finding occur, it may be essential to track previous donation history e.g. when HCV testing was introduced and regular blood donors were identified as having $\mathrm{HCV}$, it was essential to be able to track previous donations (blood, cells or tissue) via traceability to follow up potentially infected recipients. This might mean creating a unique identity for individuals.

In addition, regulatory requirements on data retention mean that traceability records have to be retained in an accessible manner for long periods of time (European Directive requires information to be stored for 30 years from the time of clinical use).

Retaining such large amounts of information for long periods in a format that allows rapid retrieval demands the use of computer data storage. In order to ensure a complete and secure information trail across the multiple computerized systems that may be involved, a means of uniquely identifying each donation, and each product prepared from that donation, is essential. Uniqueness at national or regional level is not sufficient when tissue can travel worldwide. A globally unique identification system is required, and this should extend across all biologic materials—blood, cells, tissues and organs. 
A common coding system does not imply common traceability systems, however adopting a common coding system simplifies the interfaces between different traceability systems and reduces the risk of breaks in the traceability chain.

Nomenclature as a first step in harmonizing coding

Building an internationally standardized terminology that can be represented in an electronic form on a label is a complex activity. A useful model has been described based on a five-layer pyramid (Ashford 2006).

The base layer of the model, on which the others layers are built, is the Terminology. Taking individual terms and providing a clear and unambiguous definition, build the terminology. The 'granularity' or level of detail of this terminology is important. Too little detail will result in clinically distinct products having the same name, whereas too much detail will result in an explosion of different codes for what is essentially the same clinical product. In order to achieve the appropriate level of detail it is necessary to bring together an expert international panel. The production of an international dictionary provides a way of ensuring a common understanding of the information itself.

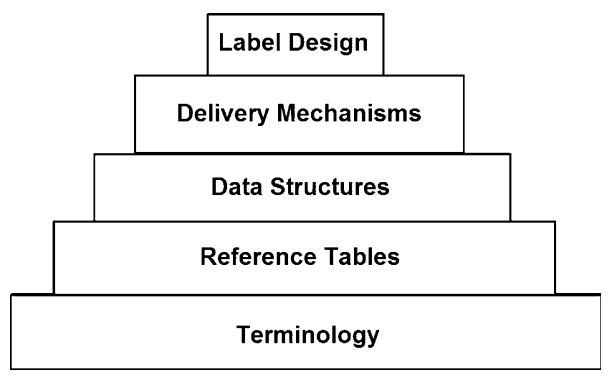

Once definitions have been agreed, then it is possible to start building the reference tables that provide the key lookup for the standard. These tables provide the mapping from the verbal description that is understood by users of the system, to the alphanumeric codes used in computer systems and electronic information carriers such as bar codes.

The Reference Tables ensure consistent interpretation of the coded information across multiple platforms. Because of the rapidly changing transfusion and transplantation environment these tables need to be flexible and readily updated within a strictly managed process.
The next level is described as the 'Data Structures'. These are only really of interest to the software developers who write or read electronic information, but they are an essential element as they provide the context and define the structure for each piece of information. The data structures make it possible for completely different and independent computer systems to communicate effectively and safely, and prevent erroneous interpretation.

The Data Structures package information in a manner that allows it to be transferred in many different formats. The means by which the information is transferred from one place to another is the delivery mechanism.

There are a number of different delivery mechanism types. The most familiar is probably the linear barcode. This relatively simple encoding system is highly effective, but can only hold a relatively small amount of information. Demands for more information, combined with limitations on space for small containers, are driving the need for alternatives.

Two-Dimensional (2-D) or Reduced Space Symbology (RSS) codes can hold more information in a much smaller space. Radio Frequency Identification (RFID) Tags have the benefit of not requiring 'line of sight' access to read. An effective coding system is one that can be adapted for use in all these media without the need to make changes to the underlying layers of the model. The final layer of the model is the Labeling layer. Labeling provides the means of physically attaching the information to the product, and for presenting the human readable interpretation of the information.

A critical element of the labeling strategy is to ensure consistency between information stored in electronic format and that which is human readable on the label. Demand printing of bar coded labels can achieve this as both sets of information are printed at the same time.

Management of a coding system

A coding system in a rapidly developing field such as transplantation must be able to adapt to the changing information needs of the environment and thus an appropriate management system is an essential part of an effective coding system. The tasks of the management organization will include: 
1. Assignment of identifiers to tissue establishments in order to ensure global uniqueness of identifiers;

2. Maintenance of an internationally agreed terminology to describe tissue products;

3. Development and maintenance of the information standard documentation;

4. Regular updating of reference tables to reflect the development of new products and processes;

5. Communication with all stakeholders to keep them informed of changes;

6. Promotion of the standard as the global solution for transplantation.

To achieve its objectives the management organization will need to bring together experts from around the world to build the necessary consensus on terminology and will need technical committees for appropriate stakeholder engagement in the development of the standard. It will need to be a robust organization with sufficient staffing and resources, and will require a mechanism to cover its costs of operation.

Currently ICCBBA is the only organization providing a truly international coding system for biologics. Looking at the running costs of this not-for-profit organization, as presented in their annual report, one can make an estimate of the cost of providing these management arrangements. In 2008 this organization operated on a budget of just under $\$ 1 \mathrm{~m}$ US and provided the management of the ISBT 128 Standard for blood, cellular therapy, and a limited number of tissues. This is a relatively low cost considering that across all three fields of blood, cellular therapy and tissue there are now more than 3,700 ISBT 128 licensed facilities in 66 countries and ICCBBA estimate that more than 40 million products are labeled to the ISBT 128 Standard each year. There are 237 Tissue and Cell facilities in more than 30 countries currently registered with ICCBBA (ICCBBA 2009) and 27 of these have registered since the start of 2009.

\section{Progress toward international standardization for coding: the current situation}

Blood

National standards to ensure uniqueness of donation identification were introduced by many countries in the 1980s and 1990s. In some cases these were associated with the use of bar codes such as ABC Codabar. Some of these systems have been updated and continue in use today; however, there is widespread recognition of the limitations and weaknesses of Codabar as a bar code symbology and of the need to move towards an international standard. The experience in the Gulf War with units of blood labeled with Codabar but with multiple errors, demonstrated its limitations (see below).

European blood banks began adopting ISBT 128 in the late 1990s and countries in Asia and the Middle East followed. In North America, the AABB established it as a standard in 2008. It has been implemented across Canada and approximately $60 \%$ of the US blood supply with the remainder to be implemented following other software upgrades. In China, blood banks in three provinces are using ISBT 128 along with the hospitals they serve. The Japanese Red Cross uses its own coding system for blood within Japan.

Today ICCBBA reports that ISBT 128 is used for blood transfusion coding and labeling in more than 3,400 blood centers and transfusion laboratories in 49 countries worldwide and that more than 40 million blood components are identified with ISBT 128 each year. A recent survey indicates that this figure will continue to rise in the coming years (Ashford et al. 2010).

In Germany an alternative standard (Eurocode) was developed for blood transfusion use in 1998. This standard has been implemented in some blood services in Germany but has not gained widespread recognition. Other countries, such as Japan, have used their own coding systems, which are efficient within the country but are not translatable across national boundaries.

\section{Cellular Therapy}

In 2005 the Boards of Directors of AABB, American Society for Blood and Marrow Transplantation (ASBMT), American Society for Apheresis (ASFA), European Group for Blood and Marrow Transplantation (EBMT), Foundation for the Accreditation of Cellular Therapy (FACT), ICCBBA, International Society of Blood Transfusion (ISBT), International Society for Cellular Therapy (ISCT), ISCT Europe, Joint Accreditation Committee of ISCT and EBMT (JACIE), National Marrow Donor Program (NMDP) and the World Marrow Donor Association (WMDA) released a Consensus Statement confirming their 
support for the international use of ISBT 128 in the coding of hematopoietic progenitor cells and other therapeutic cell products and announcing the establishment of a co-sponsored International Cellular Therapy Coding and Labelling Advisory Group.

This group began working to expand ISBT 128 for use in the field of cellular therapy. While a number of facilities had used ISBT 128 for cellular therapy products since the late 1990s, this group greatly expanded the terms and definitions to meet evolving needs. Their work was published in a variety of journals (Ashford et al. 2007).

Beginning in 2008, ISBT 128 terminology was required by FACT, JACIE, and AABB standards for labeling cellular therapy products. The requirement by these organizations for full ISBT 128 labeling (bar codes and label design) is still a few years off to allow for enhancement of computer systems. However, some cellular therapy facilities that also handle blood are already in the process of implementing the full label and nearly 200 facilities in 36 countries are registered with ICCBBA (2008).

Currently, national coordinating centers assign donor numbers to cellular product donations. As an example, the NMDP assigns a donor number for each unrelated donor of bone marrow, cord blood or peripheral blood stems cells. If the donor gives three products over 3 days, each has the same donor number and the date makes the identifier unique for each product. In the future, products should be labeled with ISBT 128 donation numbers. Products from a donor who donates on multiple days will have a different donation identification number on each product. The donor number, which is assigned by NMDP, is in the donor record, but does not appear on the product as the unique identifier. Currently, the donor number is unique only within the country and thus the unique identifier on the product is unique only within the country. There is a need to move to the system of a donation identifier on each product to be unique internationally.

\section{Tissues}

Currently identification systems for tissues range from the use of tissue bank assigned identifiers, which are only unique within the specific tissue bank to use of ISBT 128 globally unique identifiers.
In the USA, a typical numbering system is based on the year of tissue recovery followed by a sequence number, thus the first recovery of 2009 is identified as 09/001. Many tissue banks use this system thus there will be tissue grafts from multiple donors carrying the same identifier. Only when the tissue bank name is associated with this identifier is national uniqueness ensured. This duplication of identifiers presents major challenges for traceability. The Center for Disease Control is investigating the use of a national donation event identifier to overcome these difficulties.

In Italy, tissue donors are assigned an identifier at the national level by the Italian competent authority. All tissue processors, procuring tissue from the donor, use this identifier. The number is unique nationally, but does not meet an internationally agreed format and is thus unlikely to be compatible with traceability systems outside Italy.

In the UK, the National Health Service-Blood and Tissues assigns an ISBT 128 identification number to all tissues it procures. This number is unique globally and is in an international standard format, and therefore can be read and understood by all laboratories, inventory management and traceability systems that support ISBT 128 .

Most of the hospitals in China are using coding systems for cells, tissues and organs. These coding systems are usually different from one hospital to another; however, the coding for patient ID is unique in every city originally for insurance purposes. This is how a patient and his/her medical history can be traced within/among one/different hospital(s). There is little use of ISBT 128 at this stage.

Attempts at standardizing nomenclature have had limited success throughout the world. For the most part, individual Tissue Banks have their own labeling and coding scheme, which is not readable by recipient hospitals and surgery centers except through manual entry. Exceptions do exist, for example, The National Health Service Blood and Transplant Tissue Services in the United Kingdom was the first to recognize the importance of international standardization of coding for tissues. They worked with ICCBBA to develop appropriate terminology and to adapt the ISBT 128 Standard to the needs of tissue banking. They fully implemented ISBT 128 for tissue in 2003 (Fehily et al. 2004). Since then, facilities in other countries, including Poland, Finland and Denmark have implemented the standard. Austria has a 
regulatory requirement to implement it for tissues but have not yet done so.

ICCBBA has set up a European Tissue Technical Advisory Group (ETTAG) and is in the process of establishing an international advisory group for eye banking. The ETTAG will focus on the specific challenges facing European countries implementing ISBT 128 and will work with the EC to develop the key code identified in the CEN report. In the US, ICCBBA has been working with the North American Tissue Technical Advisory Group (NATTAG) of the AATB to establish common terminology for tissue products, the first step in the standardization process. When this expert panel reaches consensus, their document will be circulated for comment among AATB members. Comments will be taken into consideration and final draft shared for international comment. When international consensus for terminology attained, terminology will be added to ISBT 128 Standard Terminology for Blood, Cellular Therapy and Tissue Product Descriptions.

Additionally, ICCBBA has developed a proposal for a two-phase implementation of ISBT 128 that may be a model for implementation in countries that are unable to move directly to full ISBT 128 labeling. The proposal uses a small ISBT 128 label (approx $35 \mathrm{~mm} \times 35 \mathrm{~mm}$ ) and, as a first phase, would carry a bar coded and eye readable ISBT 128 identification number with a generic product code indicating the product to be human tissue but without further definition. The ISBT 128 number could be in addition to any local numbering for an interim period allowing time for local systems to be updated to use the new number format.

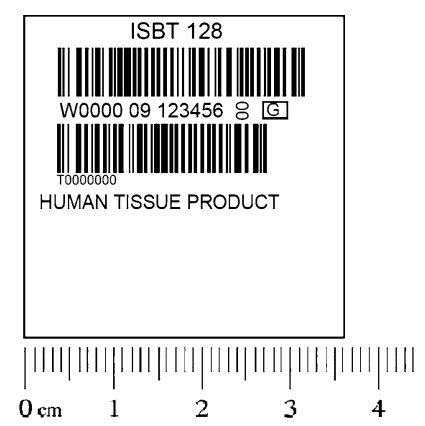

Once terminology has been agreed, the second phase incorporates the product code onto the label with minimal design change. The proposal also introduces the possibility of using 2-dimensional (Datamatrix) codes as a means of encoding more information in the space available.

Organs

As with tissue, in some countries, organ donors are assigned an identifier at the national level by the competent authority such as in Italy, or a government designated authority, such as the United Network for Organ Sharing (UNOS) in the U.S. This identifier is used by the organ recovery agency and is assigned to all organs recovered from a particular donor. The number is unique nationally, but does not meet an internationally agreed format and is thus unlikely to be compatible with traceability systems outside of the country of origin or countries that participate in the assigned system, such as Eurotransplant. This number is also not universally shared with the tissue recovery agencies that recover tissue from the same donor. Thus, the linkage is broken and communication is difficult. If an adverse event is recognized by one program, usually in the organ transplant recipient, mechanisms are lacking to convey this information to the multiple agencies involved outside of the organ transplant community. This was a serious gap recognized by the CDC in designing the TTSN.

One example of such a coding system that is currently being used for solid organ donors is the alphanumeric scheme used in the United States since the inception of the Organ Procurement and Transplantation Network (OPTN) in 1987. UNOS maintains a computer system $\left(\mathrm{UNet}^{\mathrm{SM}}\right)$ where all information about organ donors, candidates and actual organ recipients are stored. When an Organ Procurement Organization (OPO) has a potential deceased organ donor, they access the $\mathrm{UNet}^{\mathrm{SM}}$ system and generate a unique six-character alphanumeric Donor ID. The OPO uses $\mathrm{UNet}^{\mathrm{SM}}$ to make electronic offers to the transplant programs of the candidates on the list. When an organ is transplanted, the transplant program uses $\mathrm{UNet}^{\mathrm{SM}}$ to enter information on the recipient and the donor and the UNOS Donor ID links the two within the computer system.

When a disease transmission is reported to the OPTN Patient Safety System, UNOS staff can easily access the information about all other recipients of organs from the donor and contact the transplant programs that performed the transplant. The OPO is 
responsible for contacting the tissue organization that recovered and/or processed the tissue recovered from the donor. Note that $\mathrm{UNet}^{\mathrm{SM}}$ is not used to generate a UNOS Donor ID in the case of a tissue-only donor. There is currently no single coding system in the United States that is used for all organ and tissue donors.

\section{Software and instruments}

To maximize the safety and efficiency benefits of electronic data capture it is important to ensure that instruments and software used throughout the pathway from donor to recipient are able to read and correctly interpret the information provided in electronically readable format. The cost of modification of software and instruments to accommodate locally designed systems is high. Manufacturers will only include support for a coding system as a standard feature of their product if the market is sufficiently large. This presents a major obstacle for any new coding system - as illustrated by the case of ISBT 128 where it took almost ten years from the development of the standard until a significant number of manufacturers would support it as a standard feature. Today, fifteen years after ISBT 128 was developed, almost 100 vendors of software, instruments, and containers and labels are licensed with ICCBBA and support the ISBT 128 Standard. Many of these suppliers provide products that are used across all sectors (e.g. blood grouping machines, infectious disease screening systems). Several of the major software systems providers in the blood transfusion field that support ISBT 128 are now marketing systems to support cellular therapy and tissues.

\section{Coding systems for cells, tissues and organs: lessons learned and a path forward}

Lessons learned and the value of a coding system common to substances of human origin

A number of lessons from the past decade can be applied to issues of traceability and coding. The safety and traceability benefits of uniform identification combined with electronically readable information were recognized in the blood transfusion field as far back as 1976 when a system using Codabar bar codes was introduced in 16 blood centers and transfusion services in the US as part of a test program coordinated by the American Blood Commission. Following the success of this program the ABC-Codabar standard was widely adopted in the US and in several other countries (Brodheim et al. 1980; Thatcher 1981). Whilst highly successful for many years, this standard was designed for use in a 'local' context at a time when there was little movement of blood or samples outside the local blood center region, transfusion records were stored for periods of only a few years, and only a small range of blood components was prepared.

With the rapid growth in component therapy, combined with the move to larger and more centralized blood centers and testing facilities, the ABCCodabar standard was unable to cope with the more complex demands. Donation identification 'uniqueness' was constrained to the local provider (i.e. two different blood center providers could use the same 'unique' identifier). Locally introduced 'fixes' to accommodate new codes into the old structure undermined the original elements of commonality in the standard. As previously noted, the Gulf War emphasized the weakness of this system and stimulated the development of a new, internationally recognized machine-readable system.

There continues to be resistance to changing to an international standard due to a variety of reasons. There are inherent costs related to changing coding and labeling including software and hardware investments along with the inherent resistance to any change per se. This applies to both suppliers and customers who have to coordinate their systems to be compatible. There is also a small fee to register the individual institution in order to identify the sources of materials. Nevertheless, cost savings are also achieved over the long term, including personnel costs realized by adopting a standardized coding system. As an example, Diana Teo (Director of Singapore Blood Services) in the ICCBBA annual report is quoted: "ISBT 128 has provided us with an organized and consistent system of labeling for our blood and blood components. This has enabled better monitoring and more efficient management of our blood inventory. The unique format of the donation identification and product code has also contributed towards blood safety. Ultimately, the change to 
ISBT128 has been of benefit to our blood program in Singapore."

There has also been resistance to the adoption of a 'blood' standard for tissue products, however the ISBT 128 system has already been demonstrated to meet the needs of tissue banking, and ICCBBA have gone to considerable lengths to engage with the tissue and cell communities by appointing experts from these fields to their Board of Directors and establishing technical advisory groups in these fields. The benefits of a single coding system for products of human origin, both in terms of simplified handling within the hospitals, and improved biovigilance, are clear.

Currently, tissue that is received into a hospital inventory can come from as many as 40 different suppliers, each with a different labeling system and most of which are not machine-readable. This adds significant burden to the management of inventory requiring significant labor investment to $\log$ in each tissue both as received and when distributed within the hospital environment. This obviously increases risks to patient safety as it creates opportunities for error and increases the difficulty of traceability as well as the costs associated with these.

\section{Recommendations for a path forward}

There is currently a wide diversity in the identification and coding of tissue and cell products. Identification numbers are very often only unique to the cell processing laboratory or tissue bank of issue and are not always provided in an electronically readable format. Product terminology is generally not standardized even at the national level. Label design and content is varied although regulatory requirements ensure essential information is present. However, there is a slow but steady trend towards the implementation of ISBT 128. Two hundred and thirtyseven Tissue and Cell facilities in more than 30 countries are currently registered with ICCBBA to use ISBT 128, and 27 of these have registered since the start of 2009. Across all three fields of blood, cellular therapy and tissue there are now more than 3,700 ISBT 128 licensed facilities in 66 countries.

The international consensus on cellular therapy coding and labeling has set a clear direction for the global adoption of ISBT 128 for CT products. Interest in the tissue banking sector continues to grow, particularly with the recognition of the essential need for globally unique identification of tissues, however the lack of clarity over the European Commission's position on coding is hampering adoption in some European countries.

Effective traceability and biovigilance in the global context depends upon the use of globally unique identification for all donated biologic products. Where technological development permits, such identification should be provided in a standard electronically readable format to eliminate the risk of manual transcription errors. The ISBT 128 system has already been adopted in many countries, is well established, and is reliable.

In most cases mapping from existing local or national numbering systems to an ISBT 128 number should be relatively simple. The ISBT 128 Facility Identifier can be assigned at the level of individual tissue banks or organ procurement organizations, or at the level of a national coordination body. The remainder of the identifier is made up of a two-digit year code, and a six-digit sequence number. As an example, a tissue bank in the USA may currently identify tissue donations using a year code (09) and sequence number in the year (001), giving the first donor of 2009 the number 09/001. If this tissue bank were assigned the ISBT 128 facility code of W9999, then the number would map into an ISBT 128 number as W9999 09000001 , where W9999 is the facility code, 09 is the year and 000001 the sequence number for the year.

Recognizing that existing systems will need to be modified to change from current numbers to globally unique identifiers a two phase proposal from ICCBBA could be considered as an interim step.

Previously concerns have been expressed about the status of ICCBBA, in particular whether the organization is a commercial entity, and whether it is 'UScentric'. In response to such queries, ICCBBA has confirmed that they are a tax-exempt not-for-profit organization under Section 501 (c) (3) of the Inland Revenue Code which requires that the organization must not be organized or operated for the benefit of private interests, and no part of their organization's net earnings may inure to the benefit of any private shareholder or individual (IRS.gov 2010). In addition, an international volunteer Board of Directors governs ICCBBA with current members from Canada, China, Denmark, Egypt, Italy, the Netherlands, and 
the USA, and the Executive Director is based in the UK. Other resistance/perception issues include:

ICCBBA is not under the auspices of government and there is perceived risk of the system collapsing if ICCBBA fails without funding guarantees.

There are issues around who ultimately owns and controls the standard and has ultimate power over it. Another issue is the fact that the tissue banking field is competitive (and in some cases commercial) with slight variations in products using patented technologies creating unique marketable 'edges' which conflicts with the principle of commonality and product equivalence. Finally the labeling system 'looking the same' is against the principle of product branding, and highly processed grafts having unique trade names rather than product descriptions further exacerbates the issue.

Nevertheless, International standardization of terminology helps to reduce the risk of misunderstanding when product is shipped internationally and would greatly assist in the analysis of adverse events and reactions. To date the most comprehensive international terminology for biologic product descriptions is held by ICCBBA for use in the ISBT 128 Standard. However, there are some areas, most notably in reproductive tissues, eyes and organs, where the terminology has yet to be fully defined. In addition, efforts are needed to create communication pathways between the different transplant communities where a donor is shared, such as with organs, tissues and cornea programs. The identification of an adverse event, that may impact other recipients of biological components from the same donor, must be communicated to all stakeholders to improve patient safety and outcomes.

It is recommended that:

- Efforts be made to encourage the introduction of a standardized international coding system for donation identification numbers, such as ISBT 128 , for all donated human biologic products.

- Focus on global traceability for all donated human biologic products.

- Encourage communication between international stakeholders to develop consensus on common grounds.

- Promote suitable international forums to be established to expand the international terminology for donated human biologic materials.
- Any move towards adopting globally unique identification should be compatible with a well established standard coding system so that the progression towards automated data capture and computerized records can be achieved.

\section{References}

Ahn J, Cohen SM (2008) Transmission of human immunodeficiency virus and hepatitis $\mathrm{C}$ virus through liver transplantation. Liver Transplant 14(11):1603-1608

Albee FH (1912) Discussion of Carrell A: the preservation of tissues and its application in surgery. JAMA 59:527528

Ashford P (2006) ISBT 128 - improving security by international standardization. ISBT Sci Ser (1):242-245

Ashford P, Distler P, Gee A, Lakester A et al (2007) Terminology and labeling of cellular products: 1 Standards. Bone Marrow Transpl 40:1075-1083

Ashford P, Fearon M, Bedford R (2010) Report on the joint IBEPAG/ICCBBA survey on import/export and blood component labeling. Vox Sang 98:85-86

Billingham RE, Medawar PB (1951) The technique of free skin grafting in mammals. J Exp Biol 28(3):385-402

Blood Products Advisory Committee (1997) Center for Biologics and Evaluation. In: Proceedings of BPAC meeting, June 20, 1997 http://www.fda.gov/ohrms/dockets/ac/97/ transcpt/3304t2.rtf. Accessed 11 Dec 2009

Brodheim E, Ying W, Hirsh RL (1980) An evaluation of the Codabar symbol in blood banking automation. Vox Sang 40(3): $175-180$

Bush LF, Garber CL (1948) The bone bank. JAMA 137: 588-594

Carel A (1912) The preservation of tissues and its application in surgery. JAMA 59:523-527

CEN Workshop Agreement, CWA (2008) 15849. CEN Workshop Agreement on 'Coding of Information and Traceability of Human Tissues and Cells' CWA_Codingfor-T-and-C_v2000_20080522.doc. ftp://cenftp1.cenorm. be/PUBLIC/CWAs/e-Europe/Tissues_cells/CWA158492008-publishedtext.pdf. Accessed 6 Nov 2009

Chaney A (2006) "Body Brokers", Random House

CIBMTR Progress Report (2008) January-December

DeBoer HH (1986) The history of bone grafts. Clin Ortho Relat Res 226:292-298

Eastlund T, Strong DM (2004) Infectious disease transmission through tissue transplantation. In: Phillips GO (ed) Advances in tissue banking, vol 7. World Scientific Publishing Company, Singapore, pp 51-131

Eisenbrey AB, Eastlund T (eds) (2008) Hospital tissue management: a practitioner's handbook. AABB Press

Federal Register (2005) 70(106):32620-32624

Fehily D, Ashford P, Poniatowski S (2004) Traceability of human tissues for transplantation-the development and implementation of a coding system using ISBT 128. Organs Tissues 2:83-88 
Feyerick D (2009) Mayors, rabbis arrested in corruption probe. CNN.com/crime. http://edition.cnn.com/2009/CRIME/07/ 23/new.jersey.arrests/index.html. Accessed 4 Sept 2009

Fishman JA (2007) Infection in solid organ transplant recipients. N Eng J Med 357:2601-2614

Fishman JA, Strong DM, Kuehnert MJ (2009) Organ and tissue safety workshop 2007: advances and challenges. Cell Tissue Bank 10:271-280

Gandhi MJ, Strong DM (2007) Donor derived malignancy: a review. Cell Tissue Bank 8(4):267-286

IRS.gov (2010) http://www.irs.gov/charities/charitable/article/ 0, id=123297,00.html. Accessed 2 Feb 2010

Guild WR, Harrison JH, Merrill JP, Murray J (1955-1956) Successful homotransplantations of the kidney in identical twins. Trans Am Clin Climatol Assoc 67:167-173

Health Canada News Release (2005) 2005-115 Tissue Recall in the United States, October 2005

Henkel J (1994) FDA consumer magazine, vol 28, September 1994

Herman AR (2002) The history of skin grafts. J Drugs Dermatol 1(3):298-301

ICCBBA (2008) ISBT 128 cellular therapy coding and labeling advisory group 2008-a year end review, Annual Report, 2008

ICCBBA (2009) http://iccbba.org/info_abouticcbba.html. Accessed Dec 2009

Internal Revenue Service (2010) http://www.irs.gov/charities/ charitable/article/0, id $=96099,00 . \mathrm{html}$. Accessed $2 \mathrm{Feb}$ 2010

Ison MG, Hager J, Blumberg E et al (2009) Donor-derived disease transmission events in the United States: data reviewed by the OPTN/UNOS disease transmission advisory committee. Am J Transpl 9(8):1929-1935

Keller M, Grill M (2009) Inside a Creepy Global Body Parts Business. http://www.spiegel.de/international/europe/0,1518, 645375,00.html. Accessed 4 Sept 2009

Moffat SC, Cartwright VA, Stumpf PH (2005) Centennial review of corneal transplantation. Clin Exp Ophthalmol 33(6):642-647
Mroz TE, Joyce MJ, Steinmetz MP, Lieberman IH, Wang JC (2008) Perspectives in modern orthopaedics. Musculoskeletal Allograft Risks and Recalls in the United States. J Am Acad Orthop Surg 3(10):559-565

Phillips G, Strong DM (1997) The contribution of the international atomic energy agency to tissue banking. Cell Tissue Rep 4(1):5-9

Strong DM (2000) The U.S. Navy Tissue Bank: 50 years on the cutting edge. Cell Tissue Bank 1:9-16

Thatcher R (1981) Recommendations of the task force on codes and machine-readable symbols. Vox Sang 40(3): 144-155

Thomas ED, Lochte HL, Lu WC et al (1957) Intravenous infusion of bone marrow in patients receiving radiation and chemotherapy. N Engl J Med 157:491-496

Trotter JF (2008) Infectious disease risk factors of corneal graft donors. Arch Ophthalmol 126(2):235-239

Tugwell BD, Patel PR, Williams IT et al (2005) Transmission of hepatitis $\mathrm{C}$ virus to several organ and tissue recipients from an antibody-negative donor. Ann Intern Med 143:648-654

Warren J (2006) BTS stolen body parts scandal generating gruesome headlines, fears of infection; NY grand jury meeting. Transplant News, 16(1(Jan 13))

WHO (2005) Guidance on adverse event reporting and learning systems. http://www.who.int/patientsafety/events/05/ Reporting_Guidelines.pdf

WHO (2006) Human organ and tissue transplantation. Transplantation 79:635

WHO (2009) Aide-Mémoire on Access to Safe and Effective Cells and Tissues for Transplantation. http://www.who. int/transplantation/cell_tissue/en/. Accessed Nov 2009

Wilson PO (1947) Experience with a bone bank. Ann Surg 126:932-946 